\title{
Slip surface in narrow backfill behind retaining wall
}

\author{
Abdul Hakam ${ }^{*}$ and Deni Irda Mazni² \\ ${ }^{1}$ Andalas University, Civil Engineering Department, Padang, Indonesia \\ ${ }^{2}$ Dharma Andalas University, Civil Engineering Department, Padang, Indonesia
}

\begin{abstract}
For a particular area in Geotechnical engineering, a soil slope is defined as a surface of soil mass which is inclined. It the slope is unstable or has insufficient factor of safety, then it needs to be strengthened by a retaining wall or a particular earth reinforcement to ensue slope failure does not occur. It has long been known that the pattern of slip failure is classified into two main types: translation and rotation. Other patterns of slip failure can be approached within the two mentioned types above. The main purpose of this classification is to assist the engineers in the process of the the stability analysis in purpose to obtain the safety factor of the slope and the reinforcement system if any. For the retaining wall reinforcement analysis, the developed method is generally in the form of soil pressure behind the wall. The pressure due to the self weight of the soil is generated by assuming the backfill is long enough, so that the slip failure can be fully described according to the two main types above. Then in cases where the backfill behind the wall is quite narrow, the method should be corrected or modified. These narrow areas are often found on roads that are built on relatively steep slopes. In this paper, the form of the slip failure behind a narrow retaining wall is presented. The results of this study are very useful for developing analytical methods for retaining soils that are built in narrow areas due to location limitations.
\end{abstract}

\section{Introduction}

A retaining wall is a man made construction that is built to restraint the soil behind and to avoid landslides. Retaining wall is also an artificial engineered construction as a countermeasure that restrains the moving soil mass. The type of retaining wall construction made must be adapted to the purpose. In addition, the shape and geometry of the retaining wall construction must be adapted to the site conditions, including slope geometry, hydrological conditions and soil conditions. For example, when a retaining wall is constructed adjacent to an exterior basement wall, it is necessary to refer the theoretical and model tests for understanding the failure mechanism and calculating the active earth pressure [1].

The decision to take the values of the acting force or pressure is the initial stage on stability analysis. This is a very important factor on obtaining the stability of the retaining wall in the actual conditions. A study on the collapse of retaining walls has been reported by [2], become good lesson for future stability analysis of retaining walls. The report has described the case description including the failure mechanism of the retaining wall. Based on past experience, it has been showed that the failure of retaining walls is usually caused by improper design of retaining and support systems as reported by [3].

Generally, built retaining walls are in terms of cantilever type made of reinforced concrete. Another type that is very often used is the gravity wall which is made of masonry or concrete. The two types of retaining walls are very commonly used to hold soil, so the general size of these walls has been conventionally mentioned in various literature since past [4,5]. Figure 1 shows a conventional dimension of a cantilever retaining wall.

Other failure cases of retaining walls have also been discussed by various researchers such as [6], where a cantilever retaining wall designed according to the procedures in the civil engineering handbook, failed shortly after construction was completed.

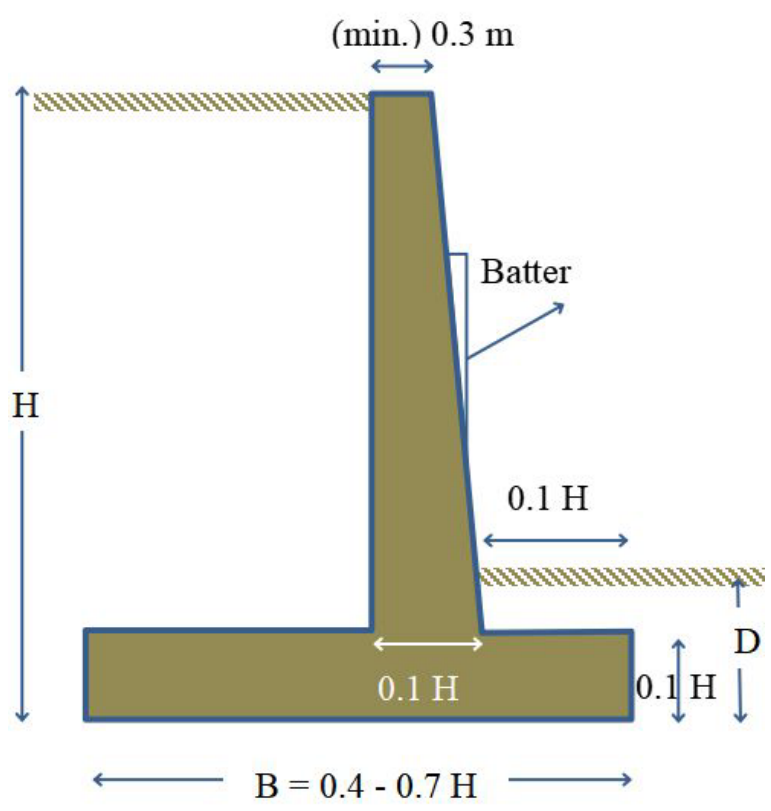

Fig. 1. Conventional dimension of a cantilever wall.

\footnotetext{
*Corresponding Author : abdulhakam2008@gmail.com
} 


\section{Methods}

\subsection{Lateral active pressure}

Lateral earth pressure caused by the soil self weight is differentiated according to its direction and mode of action. The general procedure for estimating the stability of a retaining wall begins with the step of determining the main forces acting behind the wall. This is because the main purpose of the contracting retaining wall is to restraint the soil behind the wall against sliding due to the acting forces.

The main theory for calculating the lateral pressure of soil due to its self weight was originally introduced by [7]. Furthermore [8] proposed a relatively simpler calculation procedure for calculating the lateral forces. Rankine's theory is based on the stress state in the embankment of soil mass that reaches a plastic equilibrium boundary condition where all points in the soil mass are on the threshold of shear failure (Figure 2). This theory assumes that the lateral pressure at an angle that is parallel to the slope of the backfill behind the retaining wall. By using Mohr's circle, it can be shown that the lateral deformation produces boundary conditions for determining stress with the shear strength parameters of the embankment, $\mathrm{c}$ and $\phi$.

Rankine's theory can be found in almost all soil mechanics reference books for estimating the lateral earth pressure. It is relatively easier to be understood and is often used in the stability analysis of retaining walls. Rankine's theory gives the lateral active stress due to soil weight $(\gamma)$ increases linearly as a function of depth $(z)$, and can be expressed by the equation:

$$
\mathrm{pa}=(\gamma \cdot \mathrm{z}) \mathrm{Ka}
$$

where the last term of the above equation is known as the active earth pressure coefficient, Ka:

$$
\mathrm{Ka}=\tan ^{2}(45-\phi / 2)
$$

\subsection{Laboratory experiments}

In the design of retaining walls, the existing earth pressure theories are usually used where soil pressure calculated based on the coefficient of soil pressure theory. For example, in designing a retaining wall due to seismic forces, it is conventionally done using the MononobeOkabe theory. This theory is an adaptation of the dynamic conditions of the classical Coulomb solution for the evaluation of earth pressure under static conditions.

Based on the Mononobe-Okabe theory, the effect of earthquake motion on terms of the lateral pressure acting on the wall. It can be modeled by including in the boundary equilibrium equations of the collapsed soil mass. Furthermore, the inertial forces that exist on the ground due to seismic acceleration are assumed to be constant at one direction according to the direction of the earthquake being considered.

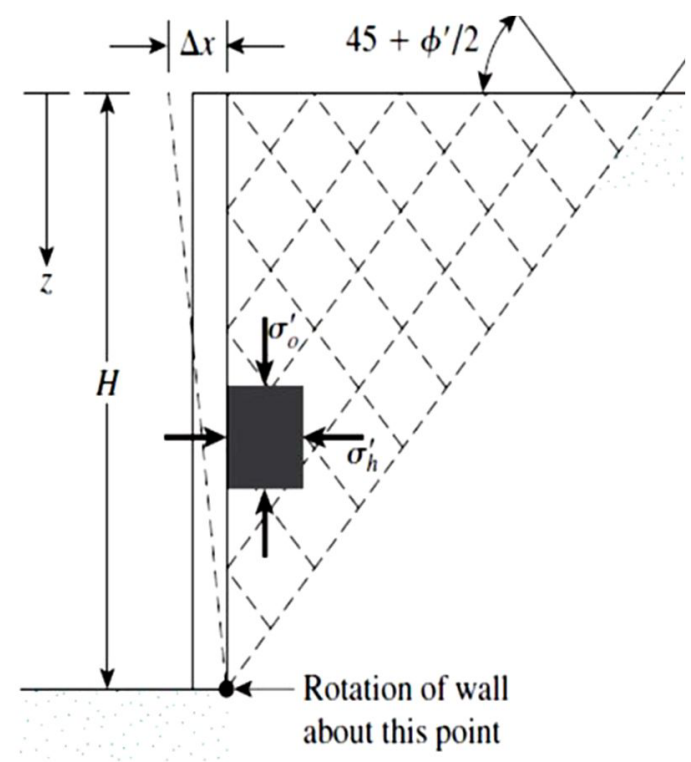

Fig. 2. Rakine's active pressure [5].

The explanation the conventional Coulomb on Mononobe-Okabe theoretical approach provides a linear seismic earth pressure distribution behind the retaining wall has been reported [9]. Furthermore, the pseudodynamic method can be used to calculate the seismically active earth pressure distribution in more realistic way. In the analysis of seismic effects, the effect of inertia on the mass of the walls and soil must be considered in the design of retaining walls.

Although the existing theories can also give quite good results, but the need for visual evidence through experimental and later test on the real cases also needs to be done. Thus the visualization resulted from the tests will become the documented evidence. Several tests to study the behavior of retaining wall systems on scaled laboratory models have been published. One example is a test on the vibrating table performs on an L-shaped retaining wall with dry sand fill, has been done by $[10,11]$. The experimental were carried out in a transparent box with records of acceleration and displacement during the tests. The experimental results are reported with the aim of providing visual and qualitative descriptions so it can be used to increase understanding of the important aspects of the behavior of retaining walls, especially due to dynamic loads. The test results of retaining wall system with horizontal embankments and inclined embankments has been carried out as shown in Fig. 3.

From these results, it can be seen that the failure line on the backfill behind the wall is in the form of a linear plane with a certain angle respect to the horizontal axis. Fig. $3 \mathrm{~b}$ shows the initial failure pattern where the shows the failure pattern still in the form of single line. For the next vibration, the failure pattern involving another angle by including larger soil masses but the failure plane is still linear.

The results of a similar test have been reported that the failure plane behind the wall due to dynamic loads is equal to or greater than active loading with an angle of $>45+\phi / 2$ degrees [12]. If the dynamic load continues to be increased, the failure plane moves slowly from a static state in terms of active stress (following the Rankine 
landslide plane) to a passive failure state with an angle of $=45-\phi / 2$ degrees. In this state a complete sliding of the wall-

wall system has occurred.
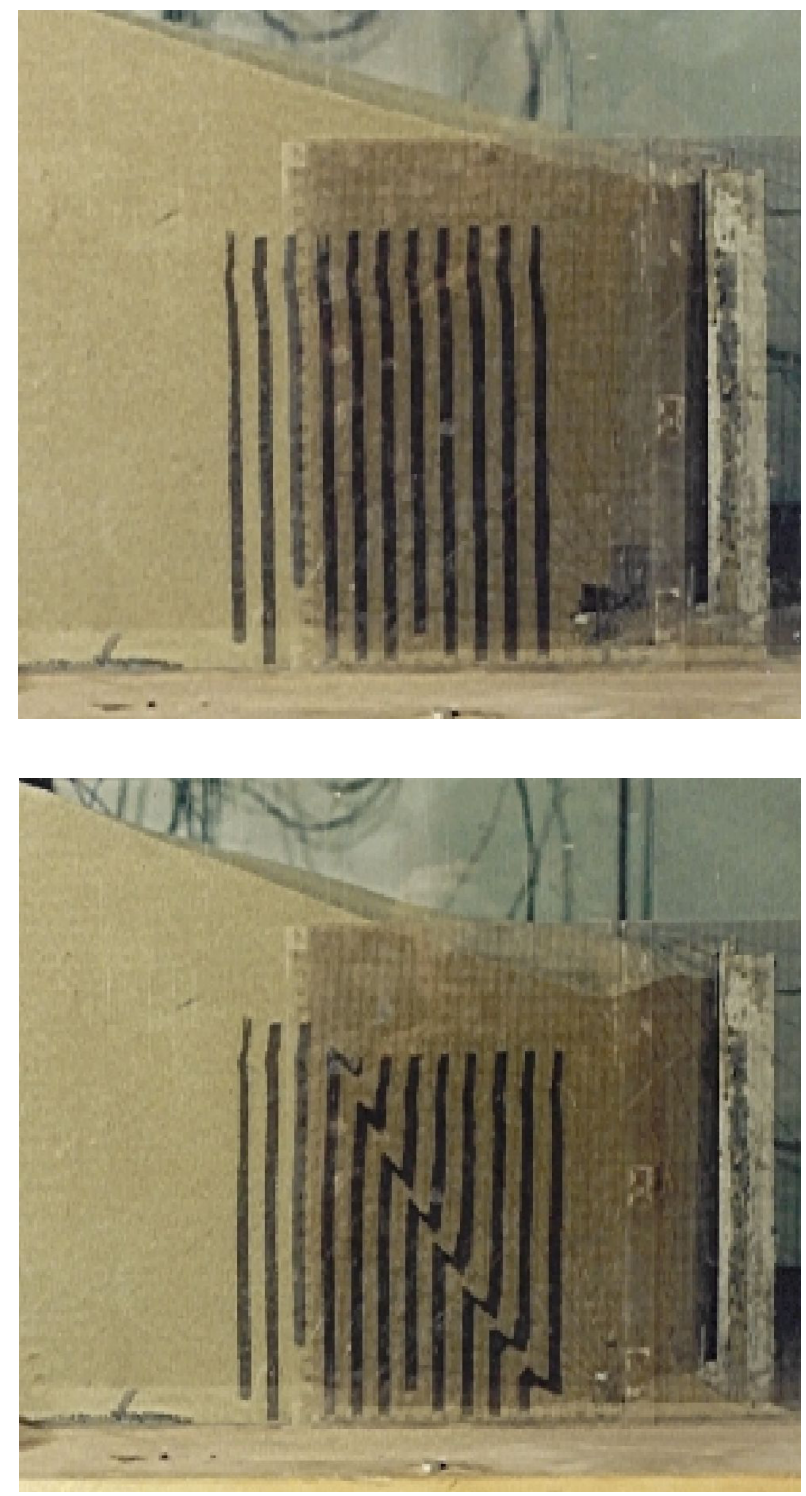

Fig. 3. Slip failure behind the wall [10].

\section{Result and Discussion}

The reported form of soil mass failure behind retaining walls generally refers to the failure of the backfill which is relatively far from the wall so that it has sufficient length to form a complete failure plane. To see the shape of the collapsed plane with a narrow fill area, an experimental retaining wall model has been carried out with the results as shown in Fig. 4.

Based on the above test results, it can be seen that the collapse occurred in the form of a linear slip failure plane. For long backfill, the collapse failure place is consistent with Rankine's theory. While the form of collapse plane on a narrow backfill, the angle of collapse is getting steeper. The failure plane on a narrow backfill will self adjust to the width of the top of the fill, so that the collapsed soil mass also decreases.
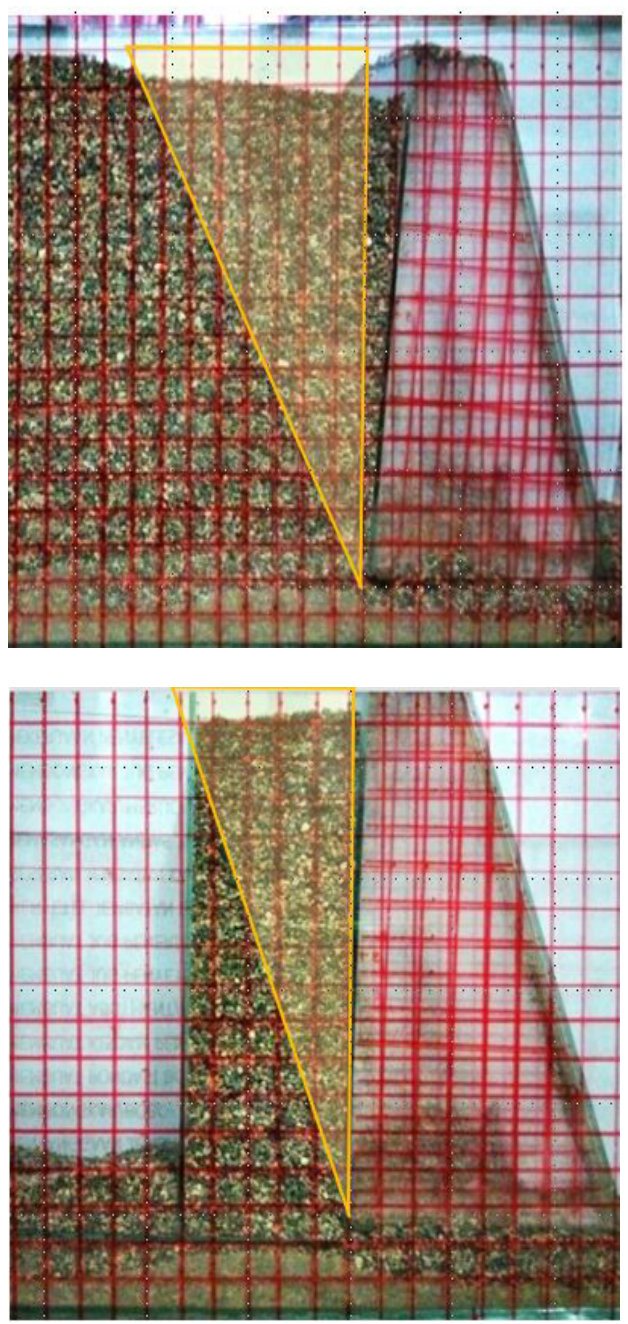

Fig. 4. Slip failure with scaled model

The form of failure plane of the soil mass behind the retaining wall to develop the theory of lateral earth pressure generally refers to the failure of the backfill which is relatively far from the wall so that it has sufficient length to build a perfect failure plane. However, for a relatively narrow backfill, then the collapse pattern will change. This was because the available area to form a Rankine-type collapse was insufficient.

It has also recently been reported that the limited use of classical failure theory for retaining walls with narrow backfill is due to the classical failure theory being developed on the assumption that there is a large space behind the wall [13]. The finite element simulation studies show that if the retaining wall moves in horizontal direction, one to three slip surfaces will be generated from the heel of the wall, and eventually expand to the surface along the wall (Figure 5).

Based on the description in the section above, it can then be derived the dominant forces acting on the retaining wall system. The values of these forces will be determined in the analysis of the stability of the retaining wall system. The values of the acting force must be considered against the dimensions of the moving mass, 
both under static loading conditions and due to seismic one.

The main thing that should be kept in mind is to pay attention to the generally accepted stability criteria. Some parameters that apply conventionally may can be shifted so that the expected construction planning can be completed with assured safety.

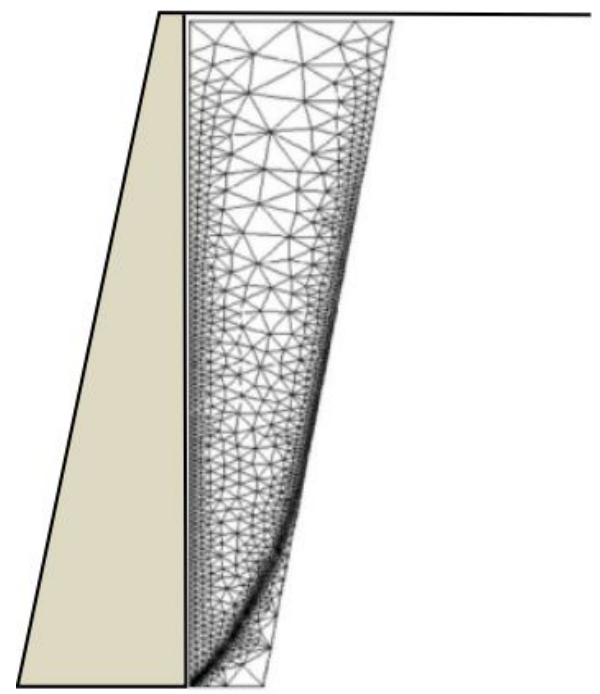

Fig. 5. Slip failure with numerical simulation [13].

\section{Conclusion}

Civil engineering practice is sometimes faced to the problems with various limitations due to the work location. The limitations of the construction site can be in terms of a small area for construction, very steep topography and sometimes unfavorable soil conditions. For this reason, to get the solution of these special cases, it is necessary to figure out the problem by considering the theories that have been developed, the studies that have been carried out, simulations in the form of numerical models as well as the experimental scaled physical models.

In this paper, a brief description of the formulation of the problem of location limitations resulting in a narrow fill, has been described. This problem arises later on in the design of retaining walls involving horizontal dimensional limitations as well as steep slopes. The solution is to figure out the problem while still considering the design procedure based on the studies that have been done and convinced by visual observations based on the results of laboratory tests.

The authors would like to thank the Department of Civil Engineering, Faculty of Engineering, Andalas University which has partially participated in providing financial support through Scopus Indexed International Publication Grants contract No. 117/UN16.09.D/PL/2021

\section{References}

1. H. Weidong, Z. Xinnian, L. Xiaohong, Z. Yongqing, and Z. Xiyu, Active Earth Pressure against Cantilever Retaining Wall Adjacent to Existing Basement Exterior Wall, Int. J. Geomech., 20, 11, 04020207 , (2020)

2. S. Sharma, Teaching Retaining Wall Design with Case Histories, Geo-Frontiers, ASCE, 2877-2886 (2011)

3. A. Lim, Lesson learned from retaining wall failures: A geotechnical disaster, MATEC Web Conf., 229 (2018)

4. J E., Bowles, Foundation Analysis and Design, 5th ed., McGraw Hill Inc, (1997)

5. B.M. Das, and K. Sobhan, Principles of Geotechnical Engineering, 8th ed., Cengage Learning (2014)

6. R.E. Olson, Failure of a Twenty-Foot High Retaining Wall, Proceedings, Missouri University of Science and Technology, Third International Conference on Case Histories in Geotechnical Engineering, 2, 791797 (1993)

7. C.A., Coulomb, Essai Sur Une Application DesRegles De Maximis Et Minimis A Quelques Problemes De Statique Relatifs A L'Architecture (Essay On Maximums And Minimums Of Rules To Some Static Problems Relating To Architecture), Mem. Acad. Roy,pres. Divers Savants, 7, Paris, 38. (1776)

8. W.J.M. Rankine, On the Stability of Loose Earth, Philosophical Transactions of the Royal Society of London (1776-1886). 1857-01-01. 147, 9-27 (1857)

9. S. Nimbalkar, A. Pain, S. Mohd Ahmad, S., and Q. Chen, Stability assessment of earth retaining structures under static and seismic conditions, Infrastructures, 4, 2, (2019)

10. E., Cascone, A.S. Lo Grasso, and M. Maugeri, Dynamic Model Tests On L-Shaped Gravity Retaining Walls, Proc. WCEE 12th, paper no. 2445.(2000)

11. E. Cascone, A.S. Lo Grasso, and M Maugeri, Dynamic Model Tests on Gravity Retaining Walls with Various Surcharge Conditions, International Conferences on Recent Advances in Geotechnical Earthquake Engineering and Soil Dynamics. 9. (2001) https://scholarsmine.mst.edu/icrageesd/04icrageesd/ session07/9

12. A. Hakam, Stabilitas Lereng and Dinding Penahan Tanah, Universitas Andalas, Padang (2010).

13. F. Chen, J. Yang, and Y. Lin,Active Earth Pressure of Narrow Granular Backfill against Rigid Retaining Wall Near Rock Face under Translation Mode, Int. J. Geomech., 19, 12, p. 04019133 (2019) 